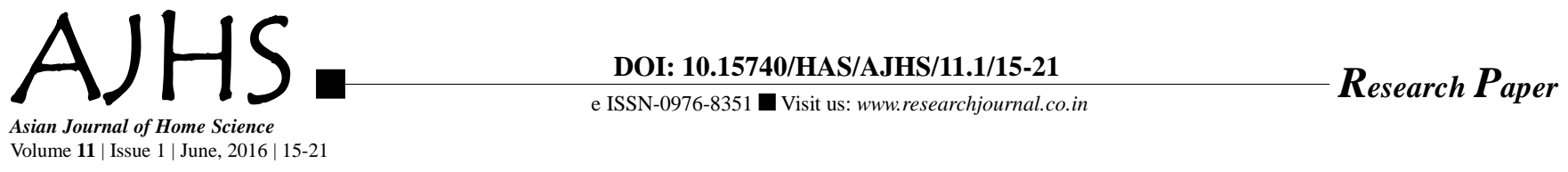

\title{
A study on difference in aggressive behaviour of adolscents boys and girls
}

\author{
VANDANA KUMARI, TEJPREET K. KANG AND REKHA KUMARI
}

Received: 10.08.2015; Revised: 19.03.2016; Accepted: 04.04.2016

See end of the paper for authors' affiliations

\section{VANDANA KUMARI}

Department of Home Science,

Govt. Girls P.G. College, GHAZIPUR (U.P) INDIA

Email : vandana_kumari12@yahoo.

com
ABSTRACT : The present study entitled "gender difference in aggressive behaviour of adolescents" was undertaken in the Ludhiana district of Punjab. The study was designed to compare aggressive behaviour of adolescent boys and girls across low and middle socio-economic strata. The sample comprised of 400 adolescents ( 200 boys and 200 girls) of the age group 1317 years equally distributed over two different socio-economic strata i.e. low and middle (200 LSES and 200 MSES). Socio-economic status scale by Bharadwaj and Buss- Durkee aggression scale by Sultania, was used in this research study. Gender differentials revealed that adolescent boys were more assaultive, negative and verbally aggressive than adolescent girls, while girls were more suspicious than boys. Low socio-economic status boys outnumbered girls in expression of negative behaviour and verbal aggression. In middle socio-economic status boys are more assaultive than girls while girls are more irritative and suspicious than boys. Mean difference showed boys exceed girls in showing assaultive behaviour, negativism and expression of verbal aggressive while girls were more suspicious than boys. Two way interaction involving socioeconomic status and gender in different dimensions of aggression showed boys with low socioeconomic status had nearly same intensity of negativism as girls with middle socio-economic status followed by boys with middle socio-economic status. The lowest level of negativism was found in girls with low socio-economic status.

KEY WORDS: Aggressive behaviour, Adolscents, Gender

- HOW TO CITE THIS PAPER : Kumari, Vandana, Kang, Tejpreet K. and Kumari, Rekha (2016). A study on difference in aggressive behaviour of adolscents boys and girls. Asian J. Home Sci., 11 (1) : 1521, DOI: 10.15740/HAS/AJHS/11.1/15-21. 